Article

\title{
Early Detection of Zymoseptoria tritici in Winter Wheat by Infrared Thermography
}

\author{
Yuxuan Wang ${ }^{1}$, Shamaila Zia-Khan ${ }^{1, *}$, Sebastian Owusu-Adu ${ }^{1}$, Thomas Miedaner ${ }^{2}$ \\ and Joachim Müller ${ }^{1} \mathbb{D}$ \\ 1 Tropics and Subtropics Group (440e), Institute of Agricultural Engineering, Universität Hohenheim, \\ Garbenstraße 9, 70593 Stuttgart, Germany \\ 2 State Plant Breeding Institute (720), Universität Hohenheim, Fruwirthstr. 21, 70593 Stuttgart, Germany \\ * Correspondence: shamaila.ziakhan@uni-hohenheim.de; Tel.: +49-711-459-24703
}

Received: 3 June 2019; Accepted: 25 June 2019; Published: 2 July 2019

\begin{abstract}
The use of thermography as a means of crop water status estimation is based on the assumption that a sufficient amount of soil moisture enables plants to transpire at potential rates resulting in cooler canopy than the surrounding air temperature. The same principle is applied in this study where the crop transpiration changes occur because of the fungal infection. The field experiment was conducted where 25 wheat genotypes were infected with Zymoseptoria tritici. The focus of this study was to predict the onset of the disease before the visual symptoms appeared on the plants. The results showed an early significant increase in the maximum temperature difference within the canopy from 1 to 7 days after inoculation (DAI). Biotic stress associated with increasing level of disease can be seen in the increasing average canopy temperature (ACT) and maximum temperature difference (MTD) and decreasing canopy temperature depression (CTD). However, only MTD $(p \leq 0.01)$ and CTD $(p \leq 0.05)$ parameters were significantly related to the disease level and can be used to predict the onset of fungal infection on wheat. The potential of thermography as a non-invasive high throughput phenotyping technique for early fungal disease detection in wheat was evident in this study.
\end{abstract}

Keywords: IR imaging; canopy temperature; maximum temperature difference; fungal infection; wheat genotypes

\section{Introduction}

Wheat is a staple food for about two billion people in the world [1]. Yield losses in agricultural production are caused by several biotic and abiotic stresses. Abiotic stresses such as frost, salinity, heat, and drought contribute to about more than $50 \%$ yield loss and are identified as the primary cause of yield loss worldwide [2-4]. Biotic factors such as pests and diseases also cause substantial damage to the crops. For example, in wheat, yield loss caused by diseases varies between 14 and 27\%, depending on the different diseases and region [5]. High yield losses are mostly observed in susceptible genotypes, which usually display high disease severity [6]. The most common fungal diseases in temperate wheat growing regions are leaf rust (Puccinia triticina), stripe or yellow rust (P. striiformis), Fusarium head blight (Fusarium spp.), powdery mildew (Blumeria graminis), and Septoria tritici blotch (Zymoseptoria tritici) [7].

The symptoms of fungal infection usually appear after a certain period of time depending on weather conditions. Early detection and diagnosis of plant pathogens can provide adequate information to predict the onset of disease and adequate measures can be taken to protect the crop before the disease is widespread [8]. There is a need for an advanced technique for rapid, accurate, and reliable detection of plant diseases especially at the time when symptoms are not yet visible on the crop [9]. Though studies have been conducted to apply imaging technologies such as fluorescence 
imaging [10], multispectral or hyperspectral imaging [11,12], and nuclear magnetic resonance (NMR) spectroscopy [13] to detect fungal diseases. However, these methods work only on a certain wavelength, which are plant and disease specific [9]. For example, Bauriegel et al. [14] detected head blight in wheat using hyper-spectral imaging in the wavelength range of $400-1000 \mathrm{~nm}$. In contrast, infrared thermography works in a wide range of wavelength and can be applied on large number of plant types and varieties. Application of infrared thermography to determine crop water status for irrigation scheduling has been established $[15,16]$. Crop water stress index (CWSI) is widely used to quantify the plant water stress based on the principle that, under water stress, plants close their stomata and this leads to the increase in leaf temperature $[17,18]$. The same principle is applied in this study, i.e., the plant transpiration and photosynthetic activity is influenced by Z $\mathrm{Z}$. tritici infection and this results in the change in canopy temperature which can be detected by thermography. The primary host penetration of $Z$. tritici occurs by penetrating the stomata 24 to 48 hours after contact with the leaf surface. About 12 days later a rapid change from the biotrophic growth stage to necrotrophic growth takes place with appearance of lesions on the leaves [19]. In cooler climates, like Germany, the occurrence of the first symptoms can be as late as 21 days after infection. This long latency period makes it difficult for the farmer to decide the correct fungicide application date. The chlorotic and necrotic symptoms of Z. tritici can lead to a decrease in leaf photosynthesis [20].

Recently, a number of studies have been conducted to determine the suitability of thermal imaging to detect biotic stress, both in the field and greenhouse: for example, the effect of downy mildew on transpiration of cucumber [21] and the effects of Z. tritici on wheat leaf gas exchange [20]. However, further studies need to be carried out in order to assess the potential of using thermography for other crops and for different locations with varying environmental conditions. The objective of this study was to detect fungal colonization at canopy level in field conditions at an early stage. The sensitivity of the methodology and the technology will be tested on different wheat genotypes. Finally, the earliest possible time of $Z$. tritici attack will be determined.

\section{Material and Methods}

\subsection{Experimental Setup and Wheat Varieties}

Twenty-five wheat varieties were planted in the field at Stuttgart-Hohenheim in a split-plot design with three replications. The main plots consisted of the two treatments (non-inoculated, artificially inoculated by Z. tritici) that were arranged in a complete randomised block design, the subplots of the 25 wheat varieties were randomized according to a $5 \times 5$ lattice design. Each plot was sown by 60 seeds in two rows $1.2 \mathrm{~m}$ long with a distance of $0.21 \mathrm{~m}$ between rows resulting in an area of $0.5 \mathrm{~m}^{2}$ per variety. Each main plot was separated by a strip of tall-growing winter triticale ("Cando") to prevent the spreading of the pathogen by spray drift during inoculation or secondary spore production. Likewise, a strip of winter rye around the experimental field as a border was planted.

The seeds were sown on 6 October 2011 by using a small tractor with a planter. No irrigation was applied throughout the growing period, as precipitation was sufficient to meet the crop water requirement. The selection of wheat varieties was done by the State Plant Breeding Institute, University of Hohenheim. In Table 1 the varieties were marked according their resistance against $Z$. tritici as classified by the German Federal Plant Variety Office [22]. 
Table 1. Tested wheat varieties and their susceptibility to Z. tritici as classified by the German Federal Plant Variety Office (Bundessortenamt, 2012); 1 = low susceptibility, 9 = high susceptibility, n.i. = no information.

\begin{tabular}{ccc}
\hline Variety & Country of Origin & Susceptibility \\
\hline Akratos & G & 5 \\
Apache & F & n.i. \\
Arina & CH & n.i. \\
Batis & G & 4 \\
Biscay & G & 7 \\
Bussard & G & 7 \\
Cubus & G & 6 \\
Dream & G & $n . i$. \\
Egoist & G & 4 \\
F201-R & ROM & $n . i$. \\
Florett & G & $n . i$. \\
History & G & $n . i$. \\
Impression & G & 4 \\
Julius & G & 3 \\
MES130 & C & $n . i$. \\
Meteor & G & 4 \\
Naturastar & G & 6 \\
Nelson & G & 3 \\
Pamier & G & 3 \\
Rubens & G & n.i. \\
Sailor & G & 5 \\
Skalmeje & G & 4 \\
Solitär & G & $n . i$. \\
Toras & G & 4 \\
Tuareg & G & 5 \\
\hline China, CH $=$ Switzerland F $=$ France, G Germany, ROM Romania. &
\end{tabular}

\subsection{Inoculation with Z. tritici}

Fungal spores were collected from infected wheat leaves, which were shaken before inoculation to remove the old spores. To prepare a medium for inoculation, Z. tritici was cultivated on culture medium made of $4 \mathrm{~g}$ yeast extract, $4 \mathrm{~g}$ malt extract (powdered), $4 \mathrm{~g}$ of glucose, $15 \mathrm{~g}$ of agar-agar, and $1000 \mathrm{~mL}$ distilled water. After autoclaving at $120^{\circ} \mathrm{C}$ for $20 \mathrm{~min}$ the agar was poured into petri dishes and cooled down. For propagation, Z. tritici was placed on agar and exposed to white- and UV-light (16 h daytime at $18{ }^{\circ} \mathrm{C}$ and $8 \mathrm{~h}$ night time at $12^{\circ} \mathrm{C}$ ) for $3-5$ days of incubation. For the mass reproduction of Z. tritici $150 \mathrm{~mL}$ fluid culture, made of $4 \mathrm{~g}$ yeast extract, $4 \mathrm{~g}$ malt extract, $4 \mathrm{~g}$ glucose, and $1000 \mathrm{~mL}$ distilled water, was added into a $300 \mathrm{~mL}$ Erlenmeyer flask and closed with an aluminium foil at $120^{\circ} \mathrm{C}$ for $30 \mathrm{~min}$. When the medium had cooled after autoclaving, Z. tritici was taken by an inoculation loop from the plate on which the spores were well developed and brought into the Erlenmeyer flask. The flask was placed on a shaker for 5 days under white- and UV-light in the same condition as mentioned above. The spores were counted and adjusted to a concentration of $5 \times 10^{6}$ spores $/ \mathrm{mL}$ and later used for inoculation. Finally, inoculation of Z. tritici was done for all varieties on 21 May 2012 in the field. Spores were than sprayed on the fully developed flag leaves of the wheat plants by using a knapsack sprayer with a constant air pressure.

\subsection{Acquiring Thermal Images}

An infrared camera (VarioCAM ${ }^{\circledR}$, InfraTec GmbH, Dresden, Germany) was used for thermal imagining. Images were acquired from 17 May until 28 June 2012 between 13:00 and 14:00 to minimize the influence of changing solar angle. Images were taken only on the sunny days when transpiration 
rate of the crop was high. Each thermal image comprised two wheat varieties as shown in Figure 1A,B. The thermal images were analysed using thermography software IRBIS (InfraTec GmbH, Dresden, Germany) and the chosen value for emissivity was 0.95 . To differentiate between canopy and soil surface, an upper temperature threshold was defined and pixels with higher temperature were excluded by image processing, Figure 1C. A polygon was manually drawn along the canopy area for each variety representing the crop temperature, Figure 1D. The average crop temperature (ACT) was calculated from the pixels within the canopy polygon and calculated as

$$
A C T=\frac{\sum T_{\text {Pixel }}}{n_{\text {Pixel }}}
$$

The maximum temperature difference (MTD) within the canopy polygon for each variety was calculated as

$$
M T D=T_{\text {Pixel, } \max }-T_{\text {Pixel, } \text { min }}
$$

The canopy temperature difference (CTD) was defined as

$$
C T D=T_{a i r}-A C T
$$

where, air temperature $T_{\text {air }}$ was measured by the weather station installed at the station.
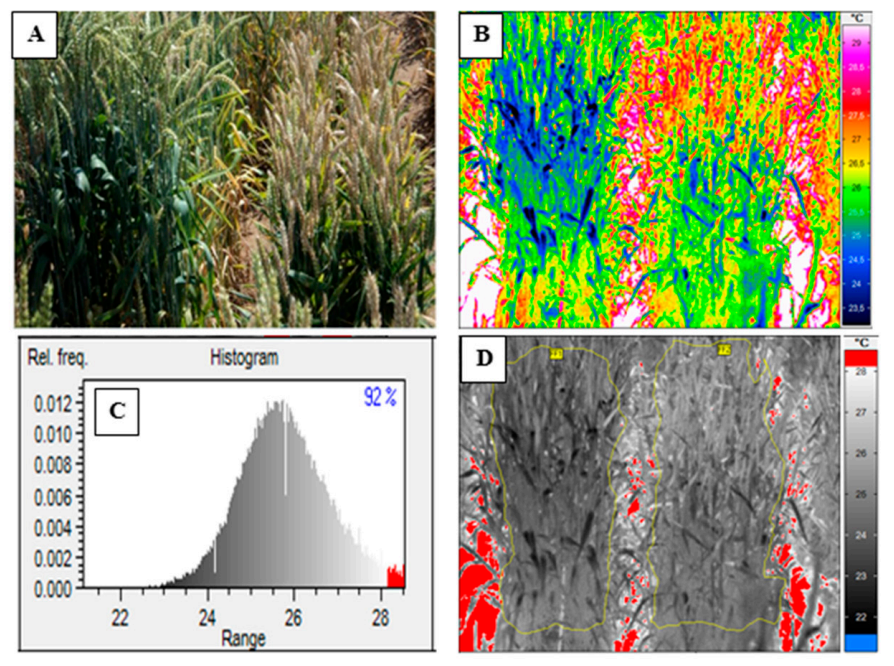

Figure 1. Canopy temperature measurement, (A) visual image, (B) thermal image, (C) histogram with upper temperature threshold, (D) polygons for calculating crop temperature.

\subsection{Visual Scoring}

The visual scoring was done by an experienced staff on plot basis. Septoria tritici blotch was scored according to the severity of symptoms observed on the flag leaf and ranged between $0 \%$ and $100 \%$. Visual scoring was done on 13 June (23 DAI), 18 June (28 DAI), 21 June (31 DAI), 25 June (35 DAI), 28 June (38 DAI), and a last time at 3 July (43 DAI).

\subsection{Data Analysis}

SPSS version 16.0 for Windows (SPSS Inc., Chicago, IL, USA) was used for analysis of variance (ANOVA) to evaluate the effect of Z. tritici infection on ACT, MTD, and CTD. A linear regression analysis was performed between the disease level and ACT, MTD, and CTD for the last day of the experiment (DAI 38) across all varieties. Furthermore, a $t$-test for mean comparison was conducted individually for each variety to determine the date when the first significant difference of ACT, MTD, and CTD to control appeared at a least significant level of 0.05 . 


\section{Results}

\subsection{Disease Level and Temperature Effects across 25 Wheat Varieties}

Figure 2 shows summarized results across all varieties at the last day of the experiment (38 DAI). The percentage of $Z$. tritici disease levels on inoculated plants was higher than the control treatment. At the end of the experiment, all the wheat varieties were Z. tritici infested irrespective of their susceptibility level to the disease. Variety "Solitär" proved to be the most Z. tritici resistant showing only $18 \%$ of disease level whereas, variety "MES130" showed the highest disease level of 93\%. ACT of the Z. tritici inoculated group showed a $2.3^{\circ} \mathrm{C}$ higher value than the control group, which was highly significant $(p \leq 0.001)$. MTD of $Z$. tritici treatment was $1.4{ }^{\circ} \mathrm{C}$ higher than that of the control group $(p \leq 0.001)$. CTD from $Z$. tritici treatment was below zero for all the varieties except of "Solitär" and "Toras", showing values of $0.27^{\circ} \mathrm{C}$ and $0.22^{\circ} \mathrm{C}$. In contrast, CTD for the control treatment was always above zero. The difference of means between treatment and control was significant $(p \leq 0.001)$.

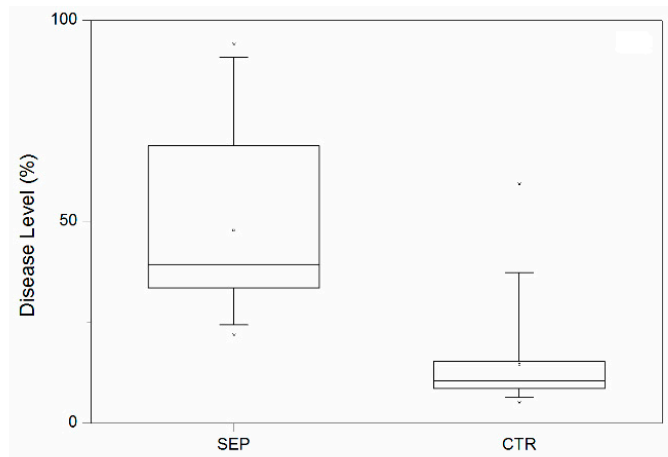

(a)

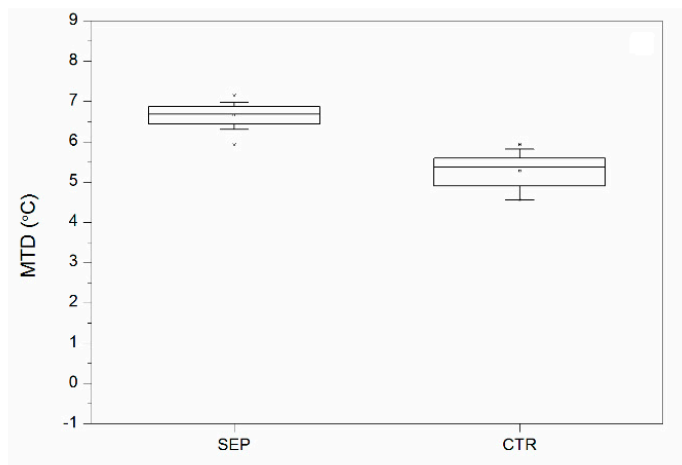

(c)

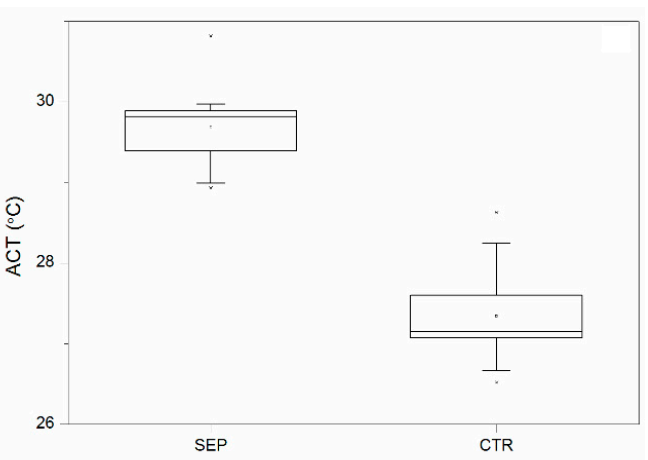

(b)

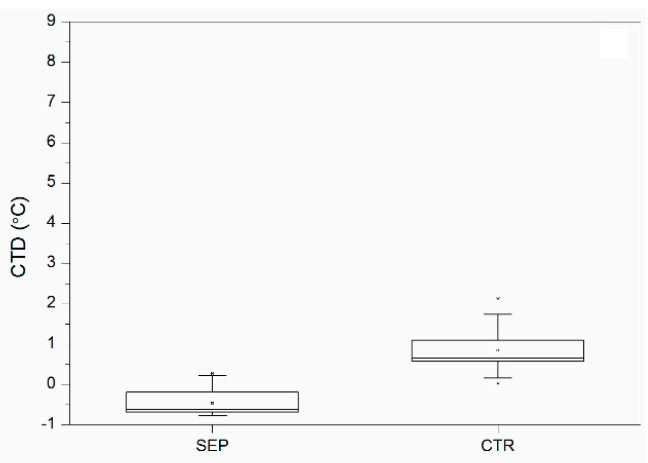

(d)

Figure 2. Crop parameters at the end of the experiment (38 DAI), summarized across 25 wheat varieties: (a) disease level, (b) average canopy temperature (ACT), (c) maximum temperature difference (MTD), (d) canopy temperature difference (CTD); $\mathrm{SEP}=\mathrm{Z}$. tritici treatment and CTR $=$ control.

\subsection{Temperature Effects Related to Disease Level for 25 Wheat Varieties}

ACT, CTD, and MTD on the last day of the experiment were plotted against disease level of the varieties as shown in Figure 3. It can be observed that ACT and MTD increased as the disease level increased, whereas CTD decreased with the disease severity. A stepwise regression analysis showed that CTD and MTD are the only parameters which can be used to explain the diseases level in all 25 wheat varieties. The significance level of MTD was however higher $(p \leq 0.01)$ compared to that of CTD $(p \leq 0.05)$. The estimation of the disease level of $Z$. tritici based on MTD and CTD is expressed by following equation (Adj. $\left.\mathrm{R}^{2}=0.7\right)$ :

$$
\mathrm{P}_{\text {infested area }}(\%)=-183.426+35.485 \times \mathrm{MTD}-17.192 \times \mathrm{CTD}
$$



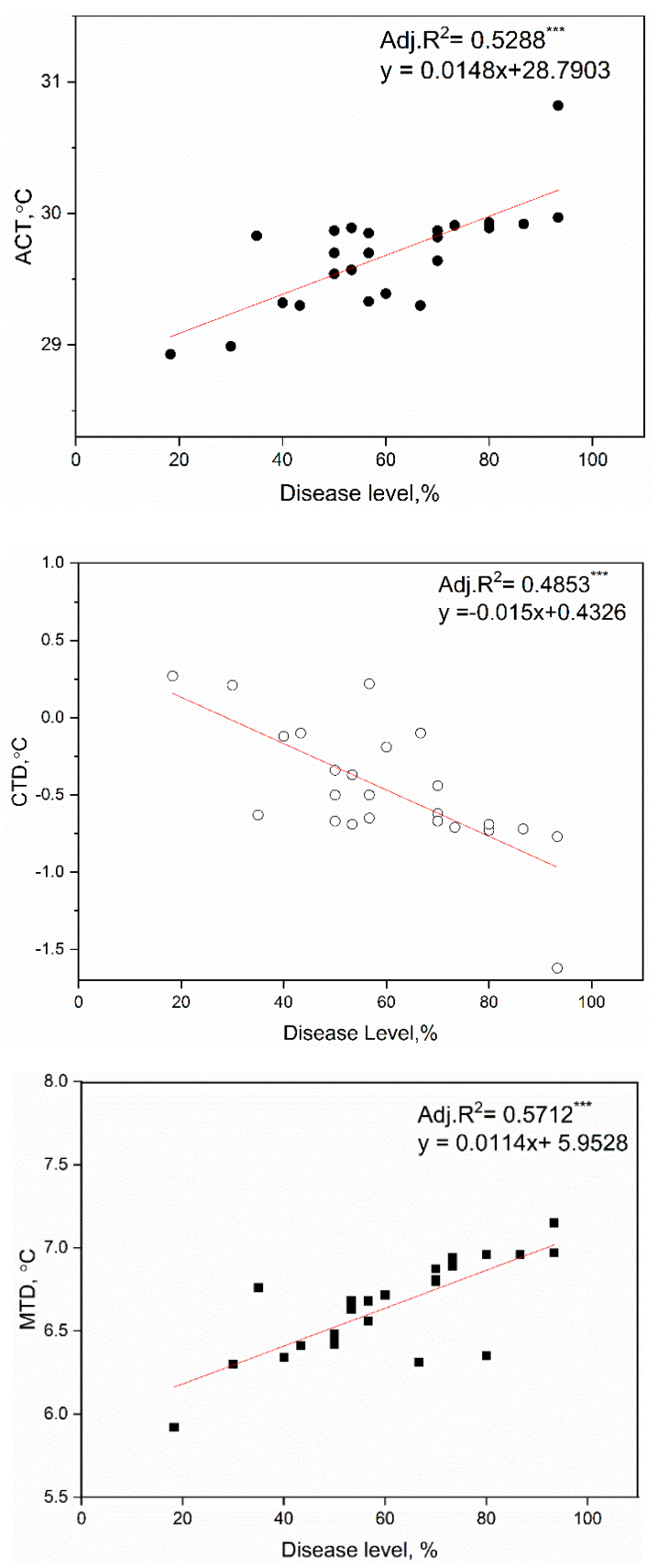

Figure 3. Regression analyses between Average Canopy Temperature (ACT), Canopy Temperature Depression (CTD), and Maximum Temperature Depression (MTD) and disease level at the end of the experiment (DAI 38) for 25 wheat varieties.

\subsection{Temperature Effect on Wheat Varieties}

As shown in Table 2, ANOVA test was conducted to compare the difference between the control and Z. tritici treatments in terms of CTD and MTD. It was observed that throughout the experiment the $Z$. tritici treatment had lower CTD than the control group and 12 varieties out of 25 showed significant difference at 0.05 levels. Before inoculation MTD of the control treatment was lower than the Z. tritici treatment however, these differences were not statistically significant. Later, after inoculation from 2 DAI till 28 DAI significant differences were observed in most of the varieties. An early significant difference in CTD and MTD were observed, this shows that these parameters can describe the health of the plant long before the naked eye observed. 
Table 2. ANOVA test between non-inoculated and Z. tritici treatment on the last day of the field experiment (38 DAI), difference in canopy temperature difference (CTD), maximum temperature difference (MTD) and the maximum difference from control treatment (DAI = days after inoculation).

\begin{tabular}{|c|c|c|c|c|c|c|c|c|c|c|c|}
\hline \multirow[t]{2}{*}{ Variety } & \multirow{2}{*}{$\begin{array}{c}\text { First Visual Symptoms } \\
\text { DAI }\end{array}$} & \multicolumn{2}{|c|}{ ANOVA Test } & \multicolumn{4}{|c|}{ Maximum Difference from Control } & \multicolumn{4}{|c|}{ First Significant Difference from Control } \\
\hline & & CTD & MTD & $\Delta \mathrm{CTD}_{\max }$ & DAI & $\Delta \mathbf{M T D}_{\max }$ & DAI & $\Delta \mathrm{CTD}$ & DAI & $\Delta \mathrm{MTD}$ & DAI \\
\hline Akratos & 23 & - & $* *$ & 2.74 & 7 & 5.42 & 38 & - & - & 1.06 & 3 \\
\hline Apache & 23 & $* *$ & - & 3.23 & 9 & 1.06 & 5 & 2.06 & 4 & - & - \\
\hline Arina & 28 & $* *$ & $* * *$ & 3.28 & 5 & 2.33 & 28 & 2.87 & 7 & 1.92 & 7 \\
\hline Batis & 23 & $* *$ & $* * *$ & 4.6 & 7 & 2.12 & 28 & 4.60 & 7 & 0.91 & 5 \\
\hline Biscay & 28 & $* *$ & $* *$ & 4.09 & 9 & 1.64 & 38 & 3.82 & 8 & 0.51 & 4 \\
\hline Bussard & 23 & $* *$ & $* * *$ & 4.31 & 28 & 2.35 & 38 & 2.61 & 7 & 0.90 & 5 \\
\hline Cubus & 23 & $* *$ & $* *$ & 3.74 & 12 & 1.35 & 38 & 1.91 & 5 & 0.78 & 4 \\
\hline Dream & 23 & - & $* * *$ & 4.88 & 3 & 2.05 & 29 & - & - & 0.81 & 4 \\
\hline Egoist & 23 & $* * *$ & $* * *$ & 3.63 & 5 & 2.21 & 28 & 2.98 & 4 & 0.45 & 3 \\
\hline F201-R & 23 & $* * *$ & $*$ & 4.25 & 7 & 1.51 & 38 & 2.34 & 4 & 0.29 & 3 \\
\hline Florett & 23 & $* *$ & - & 3.20 & 9 & 1.06 & 5 & 1.70 & 4 & - & - \\
\hline History & 23 & $* *$ & $*$ & 3.45 & 9 & 1.69 & 38 & 1.75 & 5 & 1.04 & 5 \\
\hline Impression & 23 & $* *$ & - & 3.50 & 8 & 0.98 & 26 & 1.52 & 3 & - & - \\
\hline Julius & 28 & - & $* *$ & 1.69 & 9 & 1.43 & 8 & - & - & 1.09 & 4 \\
\hline MES130 & 23 & $* * *$ & $* *$ & 3.45 & 38 & 2.12 & 38 & 1.83 & 4 & 0.86 & 7 \\
\hline Meteor & 23 & $* *$ & $* *$ & 3.41 & 3 & 1.91 & 38 & 2.24 & 1 & 1.04 & 5 \\
\hline Naturastar & 23 & $* *$ & $* * *$ & 4.03 & 7 & 2.72 & 3 & 2.22 & 4 & 1.65 & 4 \\
\hline Nelson & 23 & $* * *$ & $* * *$ & 4.54 & 9 & 2.57 & 12 & 3.51 & 4 & 1.17 & 4 \\
\hline Pamier & 23 & $* *$ & $* *$ & 3.35 & 8 & 1.86 & 5 & 2.27 & 4 & 1.86 & 5 \\
\hline Rubens & 23 & $*$ & * & 3.06 & 29 & 1.7 & 29 & 1.34 & 1 & 0.84 & 3 \\
\hline Sailor & 23 & $* * *$ & $* *$ & 3.78 & 9 & 1.15 & 9 & 3.77 & 7 & 0.95 & 5 \\
\hline Skalmeje & 28 & - & $* *$ & 2.86 & 26 & 1.49 & 1 & - & - & 1.23 & 3 \\
\hline Solitär & 28 & $*$ & - & 2.67 & 26 & 1.28 & 38 & 2.03 & 4 & - & - \\
\hline Toras & 23 & $*$ & $* *$ & 3.24 & 3 & 1.91 & 12 & 2.50 & 8 & 0.90 & 4 \\
\hline Tuareg & 23 & - & $* *$ & 2.76 & 38 & 2.01 & 7 & - & - & 1.87 & 5 \\
\hline
\end{tabular}

- Not significant, ${ }^{*}$ Significant at 0.1 levels, ${ }^{* *}$ Significant at 0.05 levels, ${ }^{* * *}$ Significant at 0.01 levels. 


\subsection{Temporal Development of Disease Level and Temperature Effects}

The development of CTD, MTD, and disease level is displayed in Figure 4. Two varieties were selected, viz. the one with the highest and the one with the lowest difference from the control during the experimental study. The variety "Dream" had the highest $\triangle C T D$ value with a twice-higher disease level $(20 \%)$ at the end of the experiment than that of Julius (10\%), which had the lowest value in $\triangle$ CTD. The CTD of the control treatment was clearly higher than that of the Z. tritici treatment throughout the experimental study of both varieties, i.e., "Dream" and "Julius".
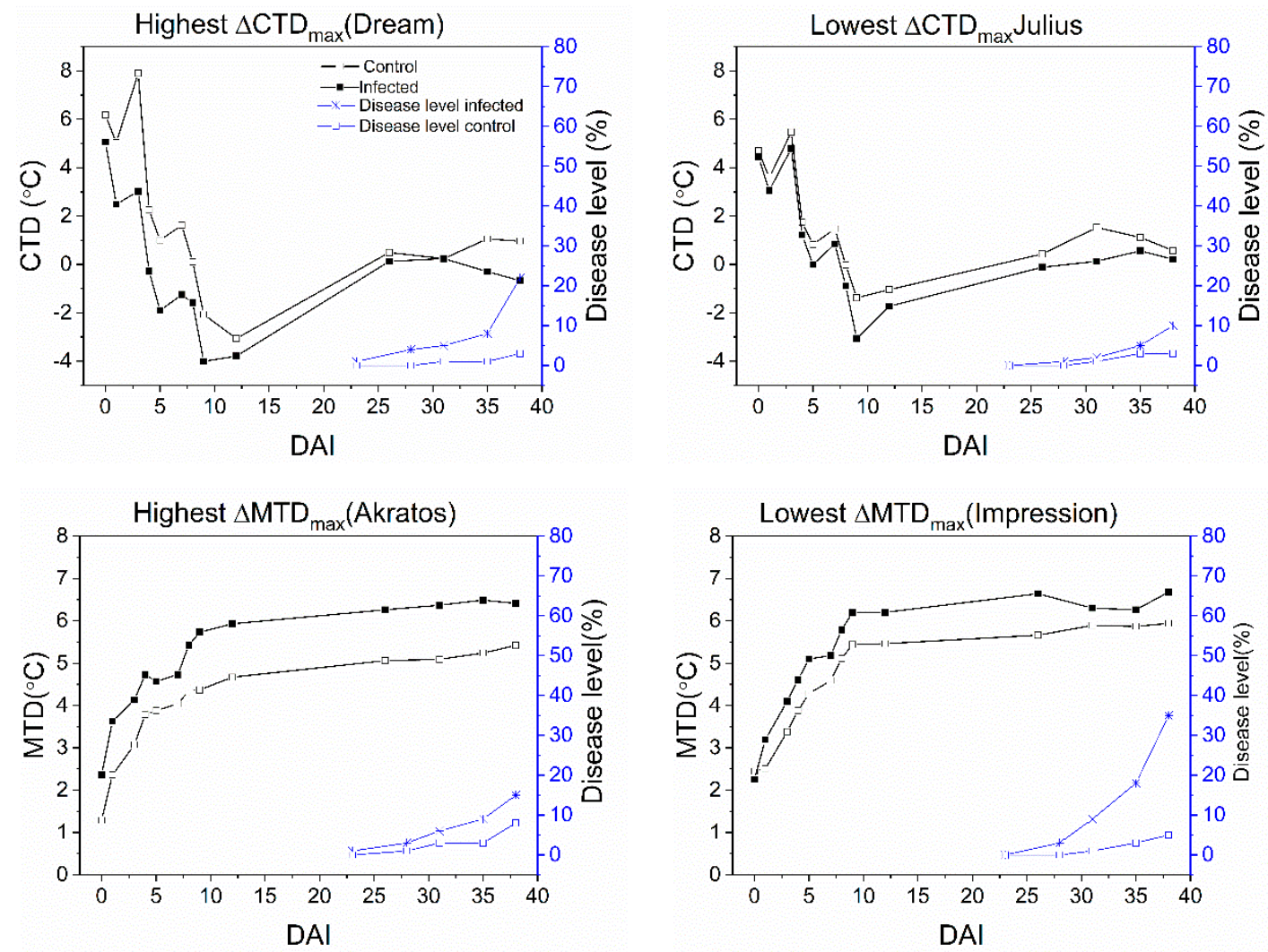

Figure 4. Effects of Z. tritici inoculation on Canopy Temperature Depression (CTD), Maximum Temperature Difference (MTD), Crop Water Stress Index (CWSI) and disease level.

The variety "Impression" had the lowest value of $\triangle \mathrm{MTD}_{\max }$ and has nearly more than doubled the disease level $(35 \%)$ of variety "Akratos" (15\%) which was the highest in $\triangle$ MTD $_{\max }$. Even though the variety "Akratos" has a similar resistance level as the variety "Impression" according to Bundessortenamt (2012) in Table 1, in Z. tritici treatment, the MTD parameter of varieties "Akratos" and "Impression" had a similar trend up to 4 DAI. However, from 5 DAI onwards, the MTD of variety "Impression" was always higher than that of variety Akratos until the end of the experiment. Though it can be seen that the difference of MTD between the varieties was not very high, it did range between $0.27^{\circ} \mathrm{C}$ and $0.53^{\circ} \mathrm{C}$. In addition, the MTD parameter of the Z. tritici was always higher than that of the control treatment in both varieties throughout the experiment.

\section{Discussion}

In this paper, Infrared thermography as a useful tool for early fungal disease detection in winter wheat was studied. Significant differences in ACT, CTD, and MTD between Z. tritici and control treatment were observed. It was interesting to find out that a significant difference in CTD, MTD was observed within a week from inoculation (Table 1) which is far earlier than the disease symptoms appeared on the plant. This is due to the fact that $Z$. tritici can germinate within $12 \mathrm{~h}$ and penetrate 
through stomata within $24-48 \mathrm{~h}$ after coming in contact depending on the climatic conditions [19]. Robert et al. [20] observed the chlorotic symptoms of Z. tritici on the flag leaves from 10 DAI and on the second leaves on 15 DAI. Plants resist the invasion of these pathogens by adopting various mechanisms such as reinforcing the cell wall, and producing compounds and inhibitors as a resistance reaction [23]. These processes could affect some of the physiological processes and could cause stress on the plant [24]. The chlorotic and necrotic symptoms of Z. tritici leads to a reduction in leaf photosynthesis [20]. However, how early the significant difference in CTD and MTD appeared was not related to the susceptibility level of wheat varieties. It agrees with the finding of Kema et al. [25] who found out that the spore germination is not influenced by the susceptibility of wheat varieties.

A decrease in CTD of Z. tritici treatment occurred as the disease level increased (Figure 3) which is caused by the reduction in the photosynthetic activity. This is in line with the results of Rosyara et al. [26] who mentioned that the stress from spot blotch caused by Cochliobolus sativus lead to a decrease in CTD because of the reduction in photosynthetic activity in infected plants whose green area is less than the healthy leaves. In addition, the invasion of these pathogens could negatively affect transpiration [27,28]. Reduction in the transpiration rate will result in higher temperature, and this could account for the reason why most of the wheat varieties showed significant differences in CTD and MTD towards the end of the experiment. Similarly, Shtienberg [28] mentioned that the colonisation and the level of damage caused by the fungi results in the reduction of photosynthesis and transpiration, and reduced transpiration would lead to a rise in the canopy temperature. The highest correlation of $R^{2}=0.6$ (Figure 3) was found between disease severity and MTD. This implies that the parameter MTD can be used as an indicator of early detection of Z. tritici in winter wheat. Also Oerke et al. [29] found out a strong correlation $\left(R^{2}=0.8\right)$ between MTD and diseased severity of cucumber with inoculation of Pseudoperonospora cubensi. In our study the result of stepwise regression showed that only MTD and CTD parameters are related with the disease level with $\mathrm{R}^{2}=0.7$ (Equation (7)). This is better than only considering one parameter for the prediction of disease level of $Z$. tritici. However, the reliability of CTD and MTD for evaluating the disease severity depends on the environmental conditions. CTD is related to ambient VPD and net radiation according to the energy balance model [30]. MTD of the leaf is also influenced by the environmental conditions such as ambient temperature and relative humidity which have an effect on the transpiration and hence on the leaf surface temperature distribution. In addition, as the disease severity increased, the CTD and MTD parameters of the healthy (control) and Z. tritici treatment became more prominent (Figure 4). This can be explained by the relationship between CTD and transpiration rate [31]. As the transpiration rate of the infected treatment decreases, the canopy temperature increases.

\section{Conclusions}

In this study, all the wheat varieties with Z. tritici showed significant differences in ACT, CTD, and MTD compared to the healthy plants (control) throughout the study period. However, only CTD and MTD parameters were significantly related to the disease level and therefore, can be used to predict the onset of fungal disease. The results showed that in some varieties, the earliest disease symptoms according to the MTD parameter could be determined as early as 3 DAI $(p \leq 0.01)$. Similarly, according to the CTD parameter, the earliest disease symptom was found as early as 4 DAI $(p \leq 0.01)$. However, in the same varieties, the first visual symptoms appeared 23 DAI. Hence, it can be concluded that thermography can be used as high throughput to accelerate monitoring of fungal disease in the field. When mounted on a drone, breeders could highly benefit from thermography for selecting disease-resistant varieties from thousands of progenies in a high-throughput manner.

Author Contributions: Data curation, Y.W. and S.O.-A.; Formal analysis, Y.W.; Funding acquisition, J.M.; Investigation, Y.W., S.Z.-K. and S.O.-A.; Methodology, S.Z.-K., T.M. and J.M.; Project administration, S.Z.-K. and J.M.; Resources, T.M. and J.M.; Software, Y.W., S.Z.-K. and S.O.-A.; Validation, S.Z.-K. and J.M.; Visualization, S.Z.-K. and J.M.; Writing-original draft, Y.W.; Writing-review \& editing, S.Z.-K., T.M. and J.M.

Funding: This work is financially supported by Deutsche Forschungsgemeinschaft (DFG), Bonn Germany. 
Acknowledgments: We are very grateful to B. Lieberherr of the State Plant Breeding Institute for her cooperation and effort in supporting the experiment.

Conflicts of Interest: Authors declare no conflicts of interest.

\section{References}

1. Siddiqui, K. Green biotechnology at the crossroads of nanobiotechnology, globalization, poverty alleviation and food sovereignty. Indian J. Crop. Sci. 2007, 2, 1-5.

2. Dhlamini, Z.; Spillane, C.; Moss, J.P.; Ruane, J.; Urquia, N.; Sonnino, A. Status of Research and Application of Crop Biotechnologies in Developing Countries: Preliminary Assessment; Food and Agriculture Organization of the United Nations: Rome, Italy, 2005.

3. Jarvis, D.; Mar, I.; Sears, L. (Eds.) Enhancing the Use of Crop Genetic Diversity to Manage Abiotic Stress in Agricultural Production Systems; IPGRI: Rome, Italy, 2006.

4. Wang, W.; Vinocur, B.; Altman, A. Plant responses to drought, salinity and extreme temperatures: Towards genetic engineering for stress tolerance. Planta 2003, 218, 1-14. [CrossRef] [PubMed]

5. Kosina, P.; Reynolds, M.; Dixon, J.; Joshi, A. Stakeholder perception of wheat production constraints, capacity building needs, and research partnerships in developing countries. Euphytica 2007, 157, 475-483. [CrossRef]

6. Ahmad, S.; Afzal, M.; Noorka, I. Prediction of yield losses in wheat (Triticum aestivum L.) in relation to epidemiological factors in Faisalabad. Pak. J. Bot. 2010, 42, 401-407.

7. Duveiller, E.; Singh, P.R.; Nicol, J.M. The challenges of maintaining wheat productivity: Pests, diseases, and potential epidemics. Euphytica 2007, 157, 417-430. [CrossRef]

8. Lucas, R.; Ubeda, A.; Paya, M.; Alves, M.; del Olmo, E.; Lopez, J.L.; San Feliciano, A. Synthesis and enzyme inhibitory activities of a series of lipidic diamine and amino alcohol derivatives on cytosolic and secretory phospholipases A2. Bioorg. Med. Chem. Lett. 2000, 10, 285-288. [CrossRef]

9. Sankaran, S.; Mishra, A.; Ehsani, R.; Davis, C. A review of advanced techniques for detecting plant diseases. Comput. Electron. Agric. 2010, 72, 1-13. [CrossRef]

10. Moshou, D.; Bravo, C.; Oberti, R.; West, J.; Ramon, H.; Vougioukas, S.; Bochtis, D. Intelligent multi-sensor system for the detection and treatment of fungal diseases in arable crops. Biosyst. Eng. 2011, 184, 311-321. [CrossRef]

11. Huang, W.; Lamb, D.W.; Niu, Z.; Zhang, Y.; Liu, L.; Wang, J. Identification of yellow rust in wheat using in-situ spectral reflectance measurements and airborne hyperspectral imaging. Precis. Agric. 2007, 8, 187-197. [CrossRef]

12. Mehl, P. Development of hyperspectral imaging technique for the detection of apple surface defects and contaminations. J. Food Eng. 2004, 61, 67-81. [CrossRef]

13. Choi, Y.; Angenot, L.; Harnischfeger, G. Analysis of Strychnos nux-vomica, Strychnos icaja and Strychnos ignatii extracts by $1 \mathrm{H}$ nuclear magnetic resonance spectrometry and multivariate analysis techniques. Phytochemistry 2004, 65, 1993-2001.

14. Bauriegel, E.; Giebel, A.; Geyer, M.; Schmidt, U.; Herppich, W.B. Early detection of fusarium infection in wheat using hyper-spectral imaging. Comput. Electron. Agric. 2011, 75, 304-312. [CrossRef]

15. Padhi, J.; Misra, R.K.; Payero, J. Prospects of using infrared thermography for irrigation scheduling of wheat crop. In Proceedings of the Australian Irrigation Conference and Exhibition 2010: One Water Many Futures, Sydney, Australia, 8-10 June 2010.

16. Zia, S.; Spohrer, K.; Merkt, N.; Wenyong, D.; He, X.; Müller, J. Non-invasive water status detection in grapevine (Vitis vinifera L.) by thermography. Int. J. Agric. Biol. Eng. 2009, 2, 46-54.

17. Jones, H.G. Use of infrared thermometry for estimation of stomatal conductance as a possible aid to irrigation scheduling. Agric. For. Meterorol. 1999, 95, 139-149. [CrossRef]

18. Jones, H.G.; Stoll, M.; Santos, T.; de Sousa, C.; Chaves, M.M.; Grant, O.M. Use of infrared thermography for monitoring stomatal closure in the field: Application to grapevine. J. Exp. Bot. 2002, 53, 2249-2260. [CrossRef] [PubMed]

19. Eyal, Z.; Sharen, A.L.; Prescott, J.M. The Septoria Diseases of Wheat, Concepts and Methods of Disease Management; CIMMYT: Texcoco, Mexico, 1987. 
20. Robert, C.; Bancal, M.-O.; Lannou, C.; Ney, B. Quantification of the effects of Septoria tritici blotch on wheat leaf gas exchange with respect to lesion age, leaf number, and leaf nitrogen status. J. Exp. Bot. 2006, 57, 225-234. [CrossRef]

21. Lindenthal, M.; Steiner, U.; Dehne, H.W.; Oerke, E.C. Effect of downy mildew development on transpiration of cucumber leaves visualized by digital infrared thermography. Phytopathology 2005, 95, 233-240. [CrossRef]

22. Beschreibende Sortenliste 2012-Getreide, Mais, Öl- und Faserpflanzen, Leguminosen, Rüben, Zwischenfrüchte; Bundessortenamt: Hannover, Deutschland, 2012.

23. Ding, L.; Xu, H.; Yi, H.; Yang, L.; Kong, Z.; Zhang, L.; Xue, S.; Jia, H.; Ma, Z. Resistance to hemi-biotrophic F. graminearum infection is associated with coordinated and ordered expression of diverse defense signaling pathways. PLoS ONE 2011, 6, 1-17. [CrossRef]

24. Kuc, J. Phytoalexins, stress metabolism, and disease resistance in plants. Ann. Rev. Phytopathol. 1995, 33, 275-297. [CrossRef]

25. Kema, G.H.J.; Sayoud, R.; Annone, J.G.; Van Silfhout, C.H. Genetic variation for virulence and resistance in the wheat-Mycosphaerella graminicola pathosystem. II: Analysis of interactions between pathogen isolates and host cultivars. Phytopathology 1996, 8, 213-220. [CrossRef]

26. Rosyara, R.U.; Subedi, S.; Duveiller, E.; Sharma, R.C. The effect of spot blotch and heat stress on variation of canopy temperature depression, chlorophyll fluorescence and chlorophyll content of hexaploid wheat genotypes. Euphytica 2010, 174, 377-390. [CrossRef]

27. Rabbinge, R.; Jorritsma, I.T.M.; Schans, J. Damage components of powdery mildew in winter wheat. Neth. J. Plant. Pathol. 1985, 91, 235-247. [CrossRef]

28. Shtienberg, D. Effect of Folia Diseases on Gas Exchange Processes: A comparative Study. Phytopathology 1992, 82, 760-765. [CrossRef]

29. Oerke, E.C.; Steiner, U.; Dehne, H.W.; Lindenthal, M. Thermal imaging of cucumber leaves affected by downy mildew and environmental conditions. J. Exp. Bot. 2006, 57, 2121-2132. [CrossRef] [PubMed]

30. Jackson, R.G.; Idso, S.B.; Reginato, R.J.; Pinter, P.J. Canopy temperature as a crop water stress indicator. Water Resour. Res. 1981, 17, 1133-1138. [CrossRef]

31. Balota, M.; Payne, A.W.; Evett, R.S.; Lazar, D.M. Canopy Temperature Depression Sampling to Assess Grain Yield and Genotypic Differentiation in Winter Wheat. Crop Sci. 2007, 47, 1518-1529. [CrossRef] 